\title{
NEVUS LIPOMATOSUS CUTANEOUS SUPERFICIALIS OF HOFFMANN AND ZURHELLE TYPE - A RARE CASE REPORT
}

Ambigai S. S. K' ${ }^{1}$ Soundarya Santhanakrishnan², Abarna Muthulakshmi3 ${ }^{3}$, M. S. Srinivasan ${ }^{4}$

${ }^{1}$ Resident, Department of Dermatology, Chettinad Hospital \& Research Institute, Kelambakkam.

${ }^{2}$ Resident, Department of Dermatology, Chettinad Hospital \& Research Institute, Kelambakkam.

${ }^{3}$ Assistant Professor, Department of Dermatology, Chettinad Hospital \& Research Institute, Kelambakkam.

${ }^{4}$ Professor \& HOD, Department of Dermatology, Chettinad Hospital \& Research Institute, Kelambakkam.

HOW TO CITE THIS ARTICLE: Ambigai SSK, Santhanakrishnan S, Muthulakshmi A, et al. Nevus lipomatosus cutaneous superficialis of Hoffmann and Zurhelle type- A rare case report. J. Evolution Med. Dent. Sci. 2017;6(78):5569-5571, DOI: $10.14260 /$ jemds/2017/1208

\section{PRESENTATION OF CASE}

A 23-year-old healthy, unmarried female came with complaints of few asymptomatic skin lesions over her left side of back since 12 years of age which progressively increased in size to attain the current size.

On examination, there were multiple, well-defined, dark brown skin coloured, nontender, compressible, soft papules and nodules coalescing to form cerebriform plaques present over left side of back involving the T7, T8, T9 dermatomes of size 10 X $6 \mathrm{~cm}$. Multiple comedo like lesions were also seen over the plaque. There were also multiple satellite papules measuring $0.5-1 \mathrm{~cm}$ in diameter from the main lesion (Figure 1). Elsewhere skin was normal.

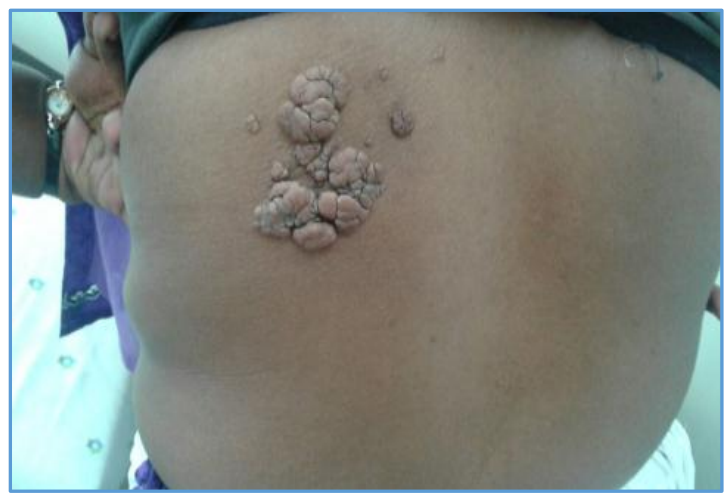

Figure 1. Multiple, Well-defined, Dark-brown Skincoloured Papules and Nodules Coalescing to form

Cerebriform Plaques present over Left Side of Back with Multiple Satellite Papules measuring 0.5-1 cm Surrounding the Main Lesion

The patient was referred for surgery and excision of the lesion was done as seen in Figures 2 and 3. Specimen sent for histopathological examination as seen in Figures $4 \mathrm{a}$ and $4 \mathrm{~b}$. Patient was followed up for 6 months and no recurrence was seen.

'Financial or Other Competing Interest': None.

Submission 22-08-2017, Peer Review 15-09-2017,

Acceptance 21-09-2017, Published 28-09-2017.

Corresponding Author:

Dr. Ambigai SSK,

\#9/17, Sri Subbiah

$9^{\text {th }}$ Lane, Sasthri Nagar,

Adyar,

Chennai-600020.

E-mail: ambigai.rulz89@gmail.com

DOI: $10.14260 /$ jemds $/ 2017 / 1208$

\section{(c) (i) $(9)$}

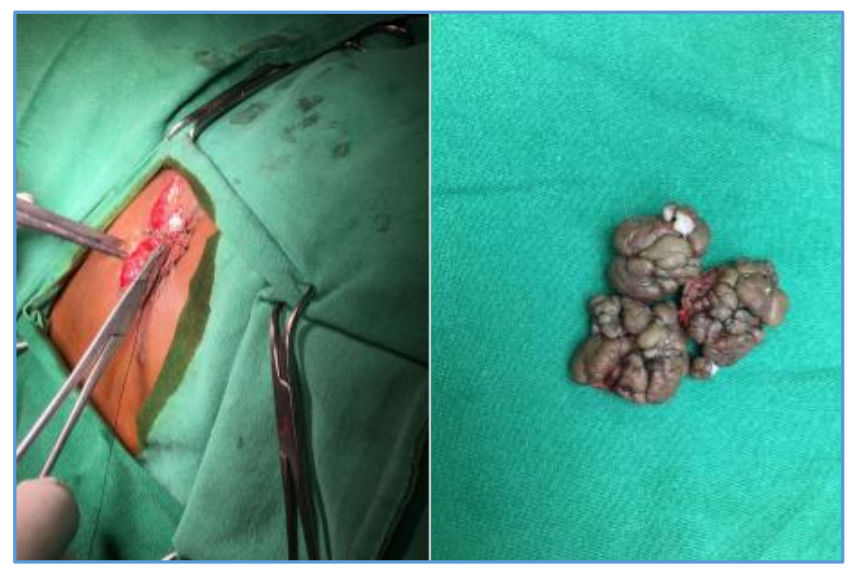

Figures 2 \& 3. Complete Excision of the Lesion was Done and Skin Sutured. The Specimen Excised is seen in the Above Image
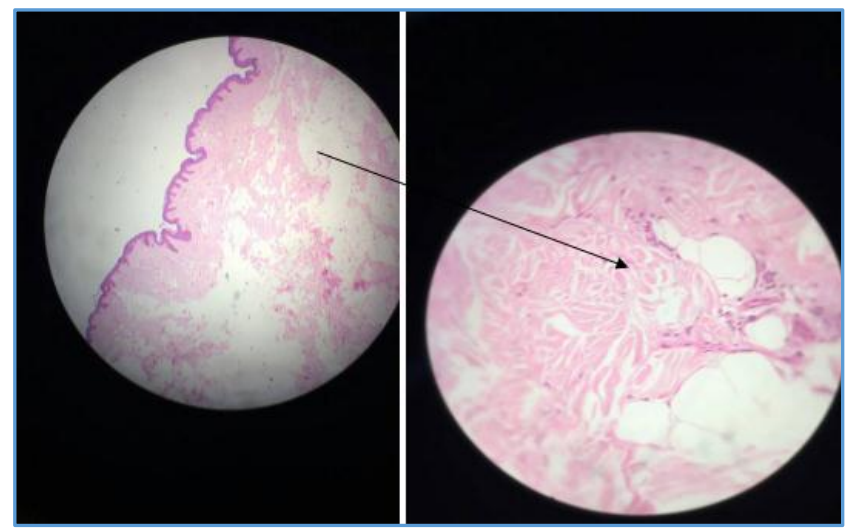

Figure 4a \& 4b. Histopathology Slide showing Epidermis with Irregular Acanthosis, Papillomatosis, Lobules of Mature Adipocytes extending from the Papillary Dermis to the Reticular Dermis, rest of the Dermis shows Collagen Bundles and mild Perivascular Lymphocytic Infiltration. Findings were Consistent with Nevus Lipomatosus (Fig.4aH\&E 40x and Fig.4b-H\&E 100x).

\section{DIFFERENTIAL DIAGNOSES}

Xanthoma, nevus sebaceous, skin tag, plexiform neurofibroma, lymphangioma, haemangioma, and focal dermal hypoplasia (Goltz syndrome) ${ }^{[1][2][3][4][5][6]}$ should be considered where histology helps in the differentiation of these conditions. No fat cells are present in the dermis in the case of skin tags. Similar dermal collections of adipocytes on histopathologic examination are also present in some melanocytic nevi, pedunculated lipofibromas, and in Goltz syndrome. Lipofibromas contain fat cells, but no skin 
appendages, in the dermis. In the case of Goltz syndrome, there is an absence of collagen in the atrophic dermis and skin appendages are absent.[7]

\section{CLINICAL DIAGNOSIS}

A possible diagnosis of Nevus Lipomatosus Cutaneous Superficialis was made based on clinical examination. Nevus Lipomatosus Cutaneous Superficialis is an uncommon nevoid anomaly of the skin. ${ }^{[8]}$ Clinically it can be classified as classical form and solitary form. The classical or multiple form was first described by Hoffmann and Zurhelle in the year 1921[9] as groups of multiple, nontender, soft, pedunculated, cerebriform, yellowish or skin-coloured papules, nodules, or plaques.[10] Hence also known as Hoffman-Zurhelle nevus. It usually presents at birth or most commonly during the first two decades of life ${ }^{[8]}$ or may begin in infancy (nevus angiolipomatosus of Howell). In which case, the replacement of hypoplastic dermis may cause pseudotumorous yellow protrusions and get associated with skeletal and other malformations, but they develop.[11] Classical lesions have a marked predilection for gluteal region, sacral and coccygeal region, lower back and upper thighs,[12] however, other sites have been described like abdomen, chest, face, ${ }^{[8]}$ perianal region, ${ }^{[7]}$ and pinna.,[13] The classical form of NLCS is usually unilateral and may be bandlike, linear, or zosteriform in distribution. The lesions continue to progress for many years, once formed, they usually remain static.[7] Occasionally, they may ulcerate with foul smelling discharge[7][3][4][14] probably owing to external trauma or ischaemia caused due to compression of the dermal vessels by ectopic fat tissue.[4]

Second more rare form is the solitary form, presenting as an asymptomatic, solitary dome-shaped papule or nodule mimicking skin tag, hence also called pedunculated lipofibroma.[15] It is commonly reported during the second decade of life and doesn't have any site of predilection as seen in classical variant. But have been reported in unusual sites like face, arms, knees, axilla, ear, scalp, ${ }^{[16]}$ palms, ${ }^{[15]}$ calf ${ }^{[2]}$ and clitoris.[17] However, both the types have clinical distinction but they both show similar histological features, with varying proportion of adipose tissue $(10 \%$ to $50 \%)$ embedded between collagen bundles of the dermis.[12]

\section{PATHOLOGICAL DISCUSSION}

Exact pathogenesis of nevus lipomatosus is not known but several other postulates were proposed such as degenerative changes or adipose metaplasia of dermal collagen and elastic tissue as the cause for the deposition of the adipose tissue within the dermis.[1][2][4][14][6]

Histopathology shows the presence of mature adipocytes in the dermis that mostly lacks any connection with the subcutaneous fat.[18]

NLCS is a rare benign hamartomatous skin condition characterised by the presence of mature ectopic adipocytes in the dermis.[7][1][11][15][5][19] The features described by Hoffman and Zurhelle such as multiple soft skin coloured, cerebriform papules and nodules coalesce into plaques were seen in our case. No gender predilection or familial predisposition was observed in the literature; however, most of the patients were females ${ }^{[5]}$ including our patient.

In a large retrospective case series, various skin abnormalities such as follicular papules, comedones, hypertrophic pilosebaceous units, angiokeratoma of Fordyce, leucoderma macules, and haemangiomas have been shown to be associated with NLCS.[11] Dhar S et al reported ulceration of the nevus. ${ }^{[3]}$

Other features such as cafe-au-lait spots, hypopigmented or leukodermic macules[8][14[20][6] and ulcerations ${ }^{[3]}$ over the lesion have been reported which were not observed in our patient.

Clinically multiple or classical forms appear as groups of multiple, nontender, soft, pedunculated, cerebriform, yellowish or skin-coloured papules, nodules, or plaques, ${ }^{[11]}$ as seen in our case. Confirmation of NLCS is done by histopathological examination.

\section{DISCUSSION OF MANAGEMENT}

Treatment is not necessary except for cosmetic purpose, ulceration or difficulty in day-to-day activities, as seen in our case. Treatment of choice is surgical excision. Recurrence following excision is rare.[21]

Patients unwilling for surgery can opt for other modalities like cryotherapy where the regression of lesion was seen with partial but satisfactory results. Other treatment modalities with variable rates of success include Intralesional sodium deoxycholate $(24 \mathrm{mg} / \mathrm{mL})$ followed by intralesional phosphatidylcholine $(50 \mathrm{mg} / \mathrm{mL}$ ) has been reported to cause clinical and histological resolution but post-injection erythema, post-inflammatory pigmentation and scarring have been observed.[18] The detergent action of sodium deoxycholate causes fat cell destruction and the released fatty acids are emulsified by phosphatidylcholine.

Hence, surgical excision is the best when compared to the rest as it can be done in a single sitting resulting in complete removal without any side effects.

\section{FINAL DIAGNOSIS}

Based on the clinical and histopathological examination, a final diagnosis of Nevus lipomatosus cutaneous superficialis was made. Here we have presented a case of giant NLCS located over the back-causing difficulty in day-to-day activities. In conclusion, we recommend early diagnosis and early excision of the lesion as the lesions continue to progress for many years. If left untreated the nodules can coalesce and reach a huge size. So far, the largest reported size is $40 \times 28$ cm. ${ }^{[8]}$ Hence, early excision eliminates extensive reconstruction of the defect and also reduces the postoperative scar formation. Excision is curative and recurrence post excision is rare.

\section{REFERENCES}

[1] Goucha S, Khaled A, Zéglaoui F, et al. Nevus lipomatosus cutaneous superficialis: report of eight cases. Dermatology and Therapy 2011;1(2):25-30.

[2] Buch AC, Panicker NK, Karve PP. Solitary nevus lipomatosus cutaneous superficialis. J Postgrad Med 2005;51(1):47-8.

[3] Dhar S, Kumar B, Kaur I. Naevus lipomatosus superficialis of Hoffman and Zurhelle. Indian J Dermatol Venereol Leprol 1994;60(1):39-40.

[4] Yap FB. Nevus lipomatosus superficialis. Singapore Med J 2009;50(5):e161-2.

[5] Prasad P. Neavus lipomatoides cutaneous superficialis. Indian J Dermatol Venereol Leprol 1995;61:243-4. 
[6] Takashima H, Toyoda M, Ikeda Y, et al. Nevus lipomatosus cutaneous superficialis with perifollicular fibrosis. Eur J Dermatol 2003;13(6):584-6.

[7] Dhamija A, Meherda A, D'Souza P, et al. Nevus lipomatosus cutaneous superficialis: an unusual presentation. Indian Dermatology Online Journal 2012;3(3):196-8.

[8] Khandpur S, Nagpal SA, Chandra S, et al. Giant nevus lipomatosus cutaneous superficialis. Indian J Dermatol Venereol Leprol 2009;75(4):407-8.

[9] Hoffmann E, Zurhelle E. Über einen naevus lipomatodes cutaneus superficialis der linken glutaalgegend. Arch Dermatol Syphilol 1921;130:32733.

[10] Pasagadugula KV, Prasad PG, Laxmi SJ, et al. Nevus lipomatosus cutaneous superficialis: poses a wholistic health problem: a case report. IOSR journal 2015;14(1):14-6.

[11] Patil SB, Narchal S, Paricharak M, et al. Nevus lipomatosus cutaneous superficialis: a rare case report. Iranian Journal of Medical Sciences 2014;39(3):304-7.

[12] Shroff HJ, Moses JM, Gadgil RK, et al. Nevus lipomatosus cutaneous superficialis. Indian J Dematol Venerol Leprol 1971;37:227-30.

[13] Ghosh SK, Debabrata B, Jamadar NS. Nevus lipomatosus cutaneous superficialis: an unusual presentation. Dermatology Online Journal 2010;16(7):12.
[14] Pathirana PW, Ranasinghe A, Perera WMT. Nevus lipomatosus cutaneous superficialis: an unusual presentation. Journal of Diagnostic Pathology 2014;8(1):59-62.

[15] Weitzner S. Solitary nevus lipomatosus cutaneous superficialis of scalp. Arch Dermatol 1968;97(5):5402.

[16] Hattori R, Kubo T, Kenji Y, et al. Nevus lipomatosus cutaneous superficialis of the clitoris. Dermatol Surg 2003;29(10):1071-2.

[17] Singh N, Kumari R, Thappa DM, et al. Classic form of nevus lipomatosis cutaneous superficialis of vulva. Indian J Dermatol Venereol Leprol 2014;80(5):473-5.

[18] Thatte SS, Bhushan P, Singh A. Nevus lipomatosus cutaneous superficialis: a report of two cases. Indian Journal of Dermatology 2016;61(1):123.

[19] Thappa DM, Sharma RC, Lal S, et al. Naevus lipomatosus cutaneous superficialis: report of 2 cases. Indian J Dermatol Venereol Leprol 1992;58(1):27-9.

[20] Cil Y, Simsek AH, Yildiz H. Sacral nevus lipomatosus cutaneous superficialis. Journal of Cutaneous and Aesthetic Surgery 2011;4(2):161-2.

[21] Al-Mutairi N, Joshi A, Nour-Eldin O. Naevus lipomatosus cutaneous superficialis of HoffmannZurhelle with angiokeratoma of Fordyce. Acta Derm Venereol 2005;86:92-3. 